\title{
CAFÉ COM AGROECOLOGIA: TECENDO DIÁLOGOS E DISCUTINDO REALIDADES
}

\author{
Jessé Rafael Bento de Lima ${ }^{1 *}$, Jonas Olímpio de Lima Silva², Luiggi Canário Cabral e Souza², Elenilton Lessa \\ Silva dos Santos ${ }^{2}$, Rafael José Navas da Silva ${ }^{3}$, Crísea Cristina Nascimento de Cristo², Ferdnando Mariano Brito \\ Silva², Clayton dos Santos Silva².
}

\begin{abstract}
${ }^{1}$ Estudante de Graduação em Agronomia, Centro de Ciências Agrárias (CECA), Universidade Federal de Alagoas (UFAL), BR 104 Norte, Km 85, Rio Largo, AL. CEP 57.000-100.

²Estudante de Graduação em Agronomia, Centro de Ciências Agrárias (CECA), Universidade Federal de Alagoas (UFAL), BR 104 Norte, Km 85, Rio Largo, AL. CEP 57.000-100.

${ }^{3}$ Professor, Centro de Ciências Agrárias (CECA), Universidade Federal de Alagoas (UFAL), BR 104 Norte, Km 85, Rio Largo, AL. CEP 57.000-100. Autor para correspondência: Jessé Rafael Bento de Lima; jesserafael.adm@hotmail.com
\end{abstract}

RESUMO: A construção do conhecimento na Agroecologia considera o processo histórico de formação coletiva e individual, na busca de um entendimento comum das relações ecológicas, sociais, econômicas e culturais dos seres humanos entre si e com a natureza. Nessa perspectiva, o Grupo Agroecológico Craibeiras (GAC) realiza mensalmente o Café com Agroecologia, este espaço é construído a partir de encontros que têm como objetivo debater e socializar temáticas relevantes ligadas à Agroecologia por meio de rodas de diálogo. A primeira edição do Café aconteceu em Fevereiro de 2016, desde então discutiu-se: "O que é Agroecologia?", "Economia Solidária e Incubação de Empreendimentos", "Desafios daAgroecologia", "Caravana Agroecológica e Cultural de Alagoas", "Do velho Chico as Ocupações", "Caminhos Regionais da Agroecologia", "Etnobiologia e Etnoecologia", "Agroecologia e Diversidade", "Saúde, segurança alimentar e nutricional e agroecologia: uma combinação saudável", "Relações indígenas e quilombolas com agroecologia", "Mulheres na Agroecologia". Nesse sentido, para além da divulgação das pautas agroecológicas, os diálogos proporcionados atuam na formação dos participantes, contribuindo para uma leitura crítica da sociedade.

PALAVRAS-CHAVE: agricultura, socialização, universidade, grupo de discussão

\section{COFFEE WITH AGROECOLOGY: WEAVING DIALOGUES, DISCUSSING REALITIES}

\begin{abstract}
The construction of knowledge in Agroecology considers the historical process of collective and individual formation, in the search for a common understanding of the ecological, social, economic and cultural relations of human beings with each other and with nature. From this perspective, the Agroecological Craibeiras Group (GAC) does the Agroecology Coffee every month, this space is built from meetings that aim to discuss and socialize relevant topics related to Agroecology through dialogue wheels. The first edition of the Coffee took place in February 2016, it was discussed "What is Agroecology?", "Solidarity Economy and Incubation of Enterprises", "Challenges of Agroecology", "Agroecological and Cultural Caravan of Alagoas", " "Agroecology and Diversity", "Health Foods and Nutrition Security and Agroecology: a Healthy Combination", "Indigenous and Quilombola Relations with Agroecology", "Agroecology and Diversity", "Women in Agroecology". In this meaning, in addition to the dissemination of the agroecological guidelines, the dialogues provided act in the formation of the participants, contributing to a critical reading of society.
\end{abstract}

KEYWORDS: Agriculture, socialization, university, discussion group.

\section{INTRODUÇÃO}

A agroecologia concebe o meio ambiente como um sistema aberto (1), composto de diversos subsistemas interdependentes que configuram uma realidade dinâmica de complexas relações naturais, ecológicas, sociais, econômicas e culturais (2). Portanto, um sistema que está muito além das teorias funcionalistas onde o conflito ocupa um lugar dinamizador na evolução das sociedades e de seu meio ambiente, porque aponta para um vínculo 
essencial que existe entre o solo, a planta, 0 animal e o homem, abrindo as portas para 0 desenvolvimento de novos paradigmas da agricultura valorizando "0 conhecimento local e empírico das agricultoras e agricultores, a socialização desse conhecimento e sua aplicação ao objetivo comum da sustentabilidade" (3). Assim, tem como um de seus princípios a participação coletiva na construção de seus conceitos, valorizando a diversidade de forma de saberes.

No Brasil, existe um número crescente de grupos e organizações com o propósito de consolidar um projeto de agricultura agroecológica, contrapondose a implantação do modelo capitalista para produção de alimentos, que explora os recursos naturais e humanos, especialmente a força de trabalho da juventude, das mulheres, das crianças e idosos, camponesas/es, indígenas, negros/as, pescadoras/es, entre outros povos tradicionais e marginalizados.

Nesse sentido, entendendo os processos de educação e formação como um dos princípios para a promoção da agroecologia, esse projeto objetiva ampliar os espaços para discussão e socialização de questões relevantes sobre ciências, sociedade, meio ambiente e cultura, colocando a agroecologia como ferramenta estratégica de resistência que incorpora um novo modo de vida, pela multiplicação e continuidade desta.

\section{MATERIAL E MÉTODOS}

\section{Contexto da Experiência}

A experiência aqui relatada envolve a comunidade que constrói a Universidade Federal de Alagoas, considerando estudantes, visitantes, agricultoras (es) e moradores do entorno.

O Café com Agroecologia acontece mensalmente em espaço público, onde através de uma exposição dialogada, convidados e público participantes interagem e discutem temas específicos. Sua primeira edição aconteceu em fevereiro de 2016, sendo iniciativa do Grupo Agroecológico Craibeiras (GAC), com a Coordenação Regional da Federação dos Estudantes de Agronomia do Brasil (FEAB).

Objetiva-se, por meio da construção das rodas de diálogo, difundir os conceitos de Agroecologia, bem como debatê-la, levando em consideração a realidade e as vivências da comunidade acadêmica, circunvizinha e dos participantes visitantes.

\section{Descrição da Experiência}

Em cada encontro dois ou três facilitadores iniciam uma fala que gira em torno de 20 a 30 minutos sobre temas previamente escolhidos, em seguida iniciam-se as discussões a partir de comentários, posicionamentos e questionamentos dos participantes, com a presença de um (a) mediador (a).

Até esse período os temas geradores foram: "O que é Agroecologia?", "Economia Solidária e Incubação de Empreendimentos", "Desafios da Agroecologia", "Caravana Agroecológica e Cultural de Alagoas", "Do velho Chico as Ocupações", "Caminhos Regionais da Agroecologia", "Etnobiologia e Etnoecologia", "Agroecologia e Diversidade", "Saúde, segurança alimentar e nutricional e agroecologia: uma combinação saudável", "Relações indígenas e quilombolas com agroecologia", "Mulheres na Agroecologia".

Neste processo, é importante ressaltar a diversidade de pessoas que constroem, quando todos têm voz ativa no diálogo, discutem e direta ou indiretamente participam do projeto, possibilitando a troca de saberes sobre ciências, sociedade, meio ambiente e cultura, com foco principal em Agroecologia.

\section{RESULTADOS E DISCUSSÃO}

Os resultados são a ampliação das trocas de experiências, saberes e sabores que partem de vários e diferentes grupos (Figura 1), como movimentos sociais, camponeses e camponesas, quilombolas, indígenas, professores e professoras, demonstram o êxito dessa experiência.

Figura 1. III Café com Agroecologia: Movimentos sociais e a luta pela terra. Fonte: os autores.

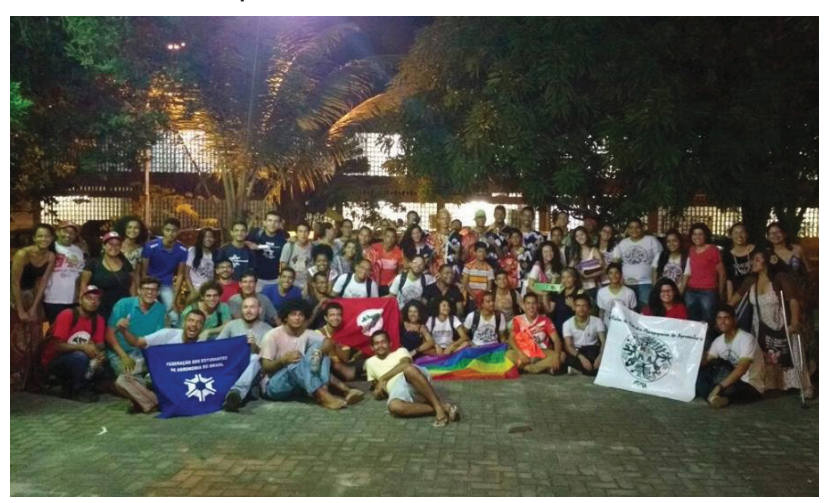

A interdisciplinaridade nos processos de construção agroecológica fica evidenciada por meio 
da interação, horizontalizada, entre diferentes áreas do conhecimento durante o Café com Agroecologia (Figura 2).

Figura 2. II Café com Agroecologia: Mulheres na Agroecologia. Fonte: os autores.

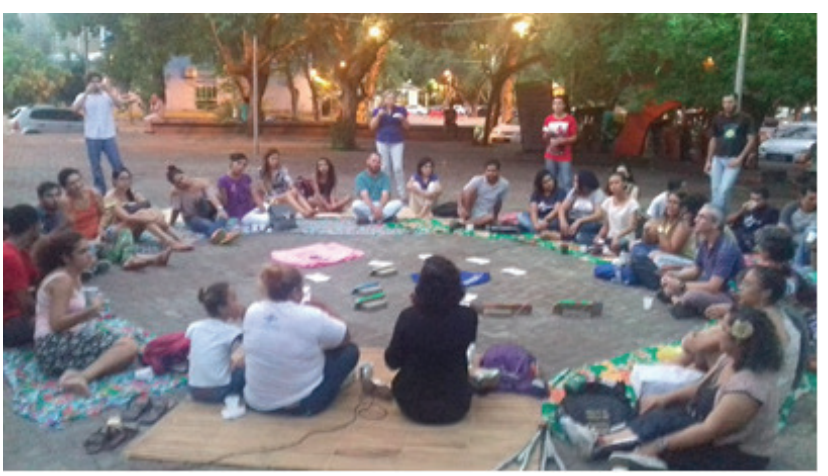

Além disto, um dos principais resultados é a partilha dos princípios e temas geradores da agroecologia dentro da sociedade, por diversificados agentes, trazendo para o cotidiano discussões que foram por muito tempo silenciadas.

Os debates promovidos não só atuaram na divulgação das pautas agroecológicas, mas também na formação dos participantes, no sentido de contribuírem para a leitura crítica da sociedade.

Através do café com agroecologia está sendo possível divulgar a agroecologia e temas correlacionados para com a comunidade universitária e circunvizinha, atuando como ferramenta de formação para crítica social por meio dos temas pautados nas rodas de diálogo.

\section{AGRADECIMENTOS}

Agradecemos o apoio financeiro disponibilizado pela Pró-reitoria de Extensão (PROEX) e Pró-reitoria de Assistência Estudantil (PROEST) da Universidade Federal de Alagoas (UFAL) para o desenvolvimento do projeto, assim como ao Centro de Ciências Agrárias, pela atenção prestada. Aos colaboradores que se dispuseram a participar e apoiar o projeto e todos aqueles que contribuíram direta ou indiretamente para o sucesso deste trabalho.

\section{REFERÊNCIAS BIBILOGRÁFICAS}

LEFF, E. Saber ambiental. México: Siglo XXI, 1998.

COSTABEBER, J.A. Transição agroecológica: do produtivismo à ecologização. Disponível em http://www. ufsm.br/desenvolvimentorural/textos/32.pdf. Acesso em: 14/03/2017.

GLIESSMAN, S.R. Agroecologia: processos ecológicos em agricultura sustentável. Porto Alegre: UFRGS, 2005. 